\title{
Erratum to: Geo-helminthiasis among migrants in Sicily: A possible focus for re-emerging neurocysticercosis in Europe
}

\author{
Ildebrando Patamia ${ }^{1}$ Piermario Nicotra ${ }^{3}$. Davide Amodeo ${ }^{1}$ Loretta Giuliano $^{2}$. \\ Calogero Edoardo Cicero $^{2} \cdot$ Alessandra Nicoletti $^{2}$
}

Published online: 19 April 2017

(C) Springer-Verlag Italia 2017

Erratum to: Neurol Sci (2017)

DOI 10.1007/s10072-017-2899-4

In the original publication, the term "geo-helminthiasis" was inappropriately used, not covering all the helminthiasis evaluated in the study. The generic term of "helminthiasis" is more appropriate.

The online version of the original article can be found at http://dx.doi. org/10.1007/s10072-017-2899-4

\footnotetext{
Alessandra Nicoletti

anicolet@unict.it

1 Dipartimento di Scienze Biomediche e Biotecnologiche, Sezione di Microbiologia, Universita` di Catania, Via Santa Sofia 89,

95123 Catania, Italy

2 Dipartimento GF Ingrassia, Sezione di Neuroscienze, Universita `di Catania, Via Santa Sofia 78, 95123 Catania, Italy

3 C.A.R.A. di Mineo Centro di Accoglienza per Richiedenti Asilo, Piazza Buglio 40, 95044 Mineo, CT, Italy
} 